\title{
El contrato de mandato: consideraciones jurídicas, tributarias y contables
}

\author{
JUAN ESTEBAn SANÍN Gómez*
}

Sumario. I. Introducción. II. Aspectos jurídicos del contrato de mandato. 1. Regulación legal. 2. La representación en el contrato de mandato y sus efectos patrimoniales III. Aspectos tributarios del contrato de mandato. 1. Aspectos tributarios generales IV. Aspectos contables del contrato de mandato. Referencias.

\section{Resumen}

El contrato de mandato se ha convertido en una importante herramienta para la realización de múltiples negocios jurídicos. El mismo tiene una doble regulación legal (desde el ámbito civil y comercial), y tiene una regulación tributaria y contable especial, por lo que resulta importante adentrarse técnicamente en su estudio, desde estas tres disciplinas, para realmente comprender el impacto que puede tener su aplicación. Lo anterior constituye, precisamente, el objeto del presente estudio.

\section{Introducción}

Dentro de los contratos de colaboración empresarial, el de mandato es quizá el más importante, no solo por ser el más utilizado, sino porque establece las bases para que del mismo se deriven otras figuras, como lo son el contrato de comisión y el contrato de agencia mercantil, entre otros. El objeto del presente estudio es analizar los efectos del contrato de mandato desde las ópticas jurídica, tributaria y contable, pues el entendimiento desde tales aspectos -que, aunque inescindibles, a veces son contradictorioses de fundamental importancia al momento de optar por su utilización.

\section{Aspectos jurídicos del contrato de mandato}

El contrato de mandato es un contrato nominado, es decir, está regulado en la ley y tiene un régimen jurídico propio. Esta

\footnotetext{
*Estudiante de la Maestría de Derecho con Énfasis en Tributación, de la Universidad Externado de Colombia; Especialista en Legislación Tributaria, Universidad Pontificia Bolivariana; Abogado de la Universidad de los Andes; socio de la firma Ignacio Sanín Bernal y Cía. Abogados, Medellín, Colombia. Correo-e: jesanin@isanin.com. Para citar el artículo: Sanín, J. E. (2016). "El contrato de mandato: consideraciones jurídicas, tributarias y contables". Revista de Derecho Fiscal n. ${ }^{\circ}$, Bogotá: Universidad Externado de Colombia. pp. 45-58. DOI: http://dx.doi. org/10.18601/16926722.n8.04
} 
regulación se encuentra tanto en el Código Civil en sus artículos 2142 y subsiguientes, como en el Código de Comercio en los artículos 1262 y subsiguientes. En virtud de lo expuesto en el artículo 822 del Código de Comercio, salvo norma expresa en contrario, y a menos que por su naturaleza no sea aplicable tal analogía, se aplicarán a los contratos de mandato comercial las normas del Código Civil que sean compatibles con su esencia.

\section{Regulación legal}

El criterio para determinar si una u otra regulación le es aplicable depende de si el encargo conferido por el mandato versa o no sobre actos de comercio. En el primer caso, le será aplicable al mismo la regulación comercial; de lo contrario, le sería aplicable la regulación civil.

Tanto la regulación comercial como la civil del contrato de mandato desarrollan los elementos esenciales, naturales y accesorios del mismo. Dentro de estos elementos se encuentran su objeto, su forma de perfeccionamiento, su revocabilidad, las obligaciones de las partes, la extensión de los efectos del encargo, las prohibiciones al mandante y la extensión de la responsabilidad del mandatario, entre otras. El régimen civil define el contrato de mandato como aquel en que una persona confía la gestión de uno o más negocios a otra, que se hace cargo de ellos por cuenta y riesgo de la primera (C.C. artículo 2142). Establece así mismo que: i) puede ser gratuito o remunerado; ii) solo existirá mandato como tal, cuando el encargo interese al mandante y al mandatario (o a un tercero); iii) es consensual y puede perfeccionarse por cualquier medio (inclusive verbalmente y mediante aceptación expresa o tácita del mandatario); iv) puede existir pluralidad de mandantes y/o mandatarios; v) el mandatario responde hasta por la culpa leve en el cumplimiento de su encargo, salvo que el mandato sea remunerado; vi) el mandatario (salvo prohibición expresa) puede delegar el encargo respondiendo por los actos de su delegado; vii) no puede el mandatario comprar las cosas que el mandante le ha ordenado vender, ni tomar en préstamo el dinero que el mandante le ha ordenado colocar a interés, salvo que medie autorización expresa del mandante; viii) no podrá el mandatario cumplir el mandato cuya ejecución sea manifiestamente perniciosa para el mandante; ix) el mandatario puede obrar con o sin representación. Si contrata a su propio nombre, no obliga respecto de terceros al mandante; ix) el mandatario habrá de responder ante terceros cuando se ha obligado personalmente o cuando no les ha dado suficiente conocimiento de sus poderes; $x$ ) el mandatario deberá rendir cuentas ante el mandante; $x i)$ el mandante tiene como obligaciones, entre otras, el proveer al mandatario con lo necesario para la ejecución de su encargo, el reembolsarle los gastos razonables causados por la ejecución del mandato, el pagarle la remuneración estipulada o usual; xii) el mandatario tendrá derecho de retención sobre los bienes del mandante para asegurar con estos el cumplimiento de las obligaciones del mandante; xiii) el mandato puede ser revocado de forma expresa o tácita (mediante el encargo del mismo negocio a distinta persona); xiv) el mandato se extingue con la muerte del mandante salvo que el mismo mandato sea destinado a ejecutarse después de ella (C.C. artículos 2143 y subsiguientes).

A su vez, el régimen comercial define el mandato como "un contrato por el cual una 
parte se obliga a celebrar o ejecutar uno o más actos de comercio por cuenta de otra" (C. de Co. artículo 1262). Dicha regulación establece que el mandato puede o no ser representativo y que por demás comprenderá los actos para los cuales haya sido conferido y aquellos que sean necesarios para su cumplimiento. Así mismo, establece que el mandatario no podrá hacer de contraparte del mandante, salvo expresa autorización de este. En cuanto al derecho del mandatario a pagarse sus créditos con las sumas del mandante que tenga en su poder, este podrá hacerlo siempre que conserve la preferencia concedida en las leyes a los salarios y demás prestaciones provenientes de la relación laboral (C. Co., artículos 1263 y subsiguientes).

El mandato puede ser revocado total o parcialmente, a menos que se haya pactado la irrevocabilidad o que el mismo se haya conferido también en interés del mandatario o de un tercero, en cuyo caso solo podrá revocarse por justa causa; en los casos en que el mandato es terminado abusivamente, (tanto por el mandante como por el mandatario) se hará exigible la correspondiente indemnización de perjuicios. Respecto del mandato conferido, también en interés del mandatario o de un tercero, este no terminará por la muerte o inhabilitación del mandante.

\section{La representación en el contrato de mandato y sus efectos patrimoniales}

Establece el artículo 2177 del Código Civil que el mandatario puede actuar con o sin representación y, que si contrata a su propio nombre (caso del mandato sin representación), no obliga, respecto de terceros, al mandante. Así mismo, el artículo 1262 del
Código de Comercio establece que el mandato puede conllevar o no la representación del mandante, y que si efectivamente la involucra, se aplicarán las normas establecidas en los artículos 832 y subsiguientes de aquel. Dichas normas indican, entre otras, que los negocios jurídicos propuestos o concluidos por el representante en nombre del representado, dentro del límite de sus poderes, producirán directamente efectos en relación con este. La regla anterior no se aplicará a los negocios propuestos o celebrados por intermediario que carezca de facultad para representar (C.C., artículo 2177 y subsiguientes).

Así pues, la representación es un efecto contractual que confiere o limita el hecho de que el mandante -frente a terceros- asuma los efectos jurídicos de los actos o contratos celebrados o ejecutados por el mandatario. Cuando el mandatario actúa en virtud de un contrato de mandato con representación, los efectos de su actuación -frente a tercerossiempre habrán de radicarse en cabeza del mandante; mientras que si actúa en virtud de un contrato de mandato sin representación, los efectos del mismo -frente a terceros- se radicarán en su propia cabeza. Debe aclararse que en múltiples escenarios jurídicos, el contrato de mandato sin representación (e inclusive el mandato mismo), no es aceptado como figura contractual válida para realizar determinados negocios.

Sobre este particular, en Concepto DIAN 037545 de 2012 estableció la entidad que la legislación aduanera vigente no consagra ni contempla la figura del mandato para actividades tales como transporte, almacenamiento o venta de productos nacionales. Por lo tanto, indica que una sucursal de sociedad extranjera no podrá otorgar mandato sin representar a una sociedad colombiana para estos fines. No obstante, 
no ocurre lo mismo con la exportación, pues allí a través de un mandato aduanero sin representación, es el mandatario quien debe aparecer registrado como exportador en la declaración de exportación, con todas las obligaciones relativas a tal calidad, incluidas las de tipo cambiario. Por tal razón, si se está actuando bajo un mandato sin representación, es claro que no pueden registrarse en la declaración de exportación características propias del mandante, por encontrarse actuando en nombre propio y no en nombre y por cuenta de aquel (Concepto DIAN 037545 de 2012).

De modo similar, la Administración Tributaria nacional, en Concepto DIAN 065122 de 2013, estableció que por estar el objeto social de las sociedades de comercialización internacional (SCI's, actualmente agencias de aduanas) circunscrito a la adquisición o compra de mercancìas que posteriormente van a ser exportadas (de acuerdo con lo establecido en el artículo 40-5 del Decreto 2685 de 1999), se excluye la posibilidad de recibir mercancías amparadas en contratos de mandato, consignación u otra forma de intermediación.

Cosa diferente sucede en la relación existente -ya no frente a terceros- sino entre el mandante y el mandatario, por cuanto, independientemente de si se actúa bajo un mandato con o sin representación de naturaleza civil o comercial, por el simple hecho de que el mandatario esté actuando "por cuenta" del mandante, los efectos patrimoniales del mencionado contrato se radican siempre en cabeza este último. Ello a raíz de que el mandatario no es otra cosa que un intermediario o facilitador que actúa "por cuenta" de su mandante, $y$ en virtud de un encargo proveído por este.
Por lo anteriormente expuesto, se ha dividido la doctrina y jurisprudencia respecto a si la representación es o no un elemento esencial del contrato de mandato. Mientras tratadistas como Fernando Hinestrosa (2008, pág. 178) apoyan la tesis de la Corte Suprema de Justicia que indica que en la legislación el mandato no es esencialmente representativo (Sentencia CSJ 07-17-1937), el Consejo de Estado y la DIAN (Concepto DIAN 0003264 de 2002) han sostenido que el contrato de mandato, respecto de la relación existente entre mandante y mandatario (y no frente a terceros), siempre es representativo (Sentencia CE-18760 de 2010 y CE-16605 de 2010). Sobre el particular, señala el Consejo de Estado:

Los efectos de la gestión realizada por el mandatario frente al tercero, cuando la realiza a título personal, a la cual alude el artículo 2177 del Código Civil, permitió concebir, en principio, la existencia de mandatos representativos y sin representación. No obstante, la discusión llevada a espacios doctrinales y jurisprudenciales ha concluido que el mandato siempre es representativo. En efecto, para algunos autores en el mandato siempre hay representación, sólo que hay ocasiones en que el mandatario actúa frente al tercero sin descubrir su calidad de tal, sin que ello haga desaparecer los efectos y cumplimiento del mandato, de suerte que al contratar lo hace en su propio nombre, y frente al mandante está cumpliendo con la obligación que se deriva del contrato de mandato, cual es la de hacer uno o varios negocios jurídicos en su nombre. Cosa distinta es que frente al tercero los efectos del acto jurídico realizado, se consideren como propios del mandatario, ya que a éste no se le puede exigir que conozca, de antemano la 
calidad o condición en la que actúa la persona con quien celebra el negocio. De allí que siempre haya representación, mirada con relación al mandante y al mandatario y no respecto de los terceros" (destacado fuera de texto) (Sentencias CE-18760 de $2010 \mathrm{y}$ CE-16605 de 2010).

\section{Aspectos tributarios del contrato de mandato}

El tratamiento tributario del contrato de mandato se encuentra establecido en el Decreto 3050 de 1997, el Decreto 1514 de 1998, el Decreto 1828 del 27 agosto de 2013 y en la Resolución DIAN 000228 de 2013 (Resolución de Información Exógena).

\section{Aspectos tributarios generales}

La regulación precedente establece, de forma clara y concreta, la dinámica fiscal que tienen los mandantes y los mandatarios en el desarrollo de un contrato de mandato. Esta dinámica puede resumirse de la siguiente forma sin perjuicio del estudio específico de la problemática de cada uno de sus ítems:

- El mandatario:
a. Factura a terceros.
b. Recibe facturas a su nombre por bienes o servicios adquiridos para el mandante.

c. Practica retenciones en la fuente en pagos a terceros, teniendo para ello en cuenta la calidad del mandante.

d. Certifica al mandante los ingresos, costos, deducciones e impuestos descontables que obtenga en virtud del mandato.

e. Declara, consigna las retenciones, expide certificados y lleva contabilidad indicativa de qué ítems se reciben para el mandante y qué gastos o costos se realizan por cuenta de aquel.

- El mandante

a. Declara los ingresos y solicita los costos, deducciones, retenciones en la fuente e impuestos descontables que le certifique el mandatario.

b. Practica retención en la fuente sobre los honorarios del mandatario.

c. Reembolsa los gastos en que incurrió el mandatario.

De lo anterior, es claro que las normas fiscales mantienen la misma lógica de las civiles y comerciales, por cuanto aunque "medie" la intermediación del mandatario, la totalidad de los efectos del negocio se radican en cabeza del mandante (Concepto DIAN 002100 de 2008).

Se trae a colación el ejemplo de la actividad hotelera, en donde el beneficio fiscal de las rentas exentas hoteleras aplica para el contribuyente mandante y no para el mandatario, por cuanto su retribución tiene diferente naturaleza. Ello aun cuando se pacte que la remuneración del mandatario será un porcentaje de las utilidades provenientes de la prestación del servicio. En Sentencia proferida por el Consejo de Estado, se ratificó el principio de transparencia en el mandato al decirse que la diferencia entre el contrato de mandato con representación y sin representación no justifica la restricción de la norma que consagra la exención del impuesto de timbre para los contratos suscritos entre las ONG y terceros, cuando las ONG actúan en desarrollo del mandato conferido por el FOREC, y tales contratos tienen por objeto cumplir el principal (Sentencia CE-16155 de 2003). 
i. Tratamiento especial del mandato en algunos impuestos

El tratamiento tributario ya descrito del contrato de mandato en los diferentes impuestos es el siguiente:

- Impuesto a las ventas

Tal como se indicó previamente, según el artículo 3 del Decreto 1514 de 1998, le corresponde siempre al mandatario expedir las facturas de compra de bienes o servicios. Ahora, el hecho de que el mandante no sea responsable del impuesto sobre las ventas no implica necesariamente que no ostente la calidad de agente retenedor del IVA, ya que, conforme al artículo 9 de la Ley 223 de 1995, son agentes de retención, entre otros, los grandes contribuyentes, sean o no responsables del IVA, y los que mediante resolución la DIAN designe como tal (destacado fuera de texto).

De tal manera que si el mandante, sin ser responsable del IVA es agente retenedor del impuesto, traslada esa calidad al mandatario, quien, entonces, "debe practicar retención en la fuente frente a terceros a título de este impuesto" (Memorando General del Contrato de Mandato. Of. Ignacio Sanín Bernal \& Cía. Abogados).

- Impuesto sobre la renta

$\mathrm{El}$ aspecto fundamental a tener en cuenta en este escenario es determinar si los ingresos percibidos por el mandatario tienen la vocación o capacidad de enriquecerlo a él o, por el contrario, si son percibidos "por cuenta" del mandante y por ende han de afectar fiscalmente a aquel. Según el artículo 26 del Estatuto Tributario, los únicos ingresos que conforman la renta líquida del contribuyente son aquellos que sean susceptibles de producir un incremento neto del patrimonio en el momento de su percepción.

La DIAN ha sido consecuente con la posición que indica que solo son susceptibles de ser gravados los ingresos que el mandatario recibe para sí; es decir, su comisión o sus honorarios, mas no aquellos que son recibidos para un tercero. En cuanto a las consignaciones que corresponden a ingresos recibidos para terceros, es del caso aclarar que, en tanto estos no son susceptibles de capitalizarse en cabeza de quien figura como intermediario, este solo debe incluir en el denuncio rentístico los ingresos propios; por ende, el beneficiario real en cuyo nombre se recibieron dichos ingresos debe reflejarlos en su declaración del correspondiente período gravable (Concepto DIAN 071921 de 2005), por cuanto sobre los mismos ha de tributar aquel (Concepto DIAN 038188 de 2012).

Otros asuntos importantes, relacionados con el tratamiento del impuesto sobre la renta en el contrato de mandato, son los siguientes:

- Los contratos de mandato internacional entre vinculados económicos, están sometidos al principio de plena competencia.

Desde el año 2008 (Concepto DIAN 002100 de 2008), la DIAN ha reconocido la validez de los contratos de mandato internacional, celebrados bajo el principio de la autonomía de la libertad de los contratantes. En el mismo Concepto indica la entidad que, en los casos de mandatarios del exterior para prestar servicios en territorio nacional, es de señalar que de acuerdo con el artículo 471 y siguientes del Código de Comercio, para que 
una sociedad extranjera pueda emprender negocios permanentes en Colombia deberá establecer una sucursal con domicilio en el territorio nacional. Así mismo, ha establecido que, cuando se cumplan los presupuestos establecidos en la legislación colombiana, habrá de darse aplicación al régimen de precios de transferencia (Concepto DIAN 057035 - 2013).

- Utilización de canales bancarios para obtener el reconocimiento fiscal de los pagos hechos por el mandatario.

Ha indicado la DIAN a través de concepto que la realización de pagos por parte de un tercero, en uso de sus propios recursos por cuenta de un contribuyente y en virtud de un convenio (contrato de mandato) tendrá reconocimiento fiscal como costos, deducciones, pasivos o impuestos descontables, siempre y cuando se utilicen los canales bancarios mencionados en el artículo 7715 del Estatuto Tributario (Concepto DIAN 066917 de 2014).

- Impuesto sobre la renta para la equidad - CREE

A partir de la expedición del Decreto 1828 de 2013, se determinó que todos los sujetos pasivos del CREE debían actuar como autorretenedores cuando recibieren pagos o abonos en cuenta sometidos al impuesto. Así, entonces, el artículo 2 (parágrafo) del Decreto en mención estableció que en los contratos de mandato, incluida la administración delegada, el mandatario se abstendrá de practicar al momento del pago o abono en cuenta la retención en la fuente del impuesto sobre la renta para la equidad CREE.
Algunos interrogantes puntuales han surgido sobre el tema, tal como pasa a explicarse:

- Determinación de los ingresos susceptibles de autorretención

Reembolso de gastos: dado que no sobre todos los pagos recibidos de terceros puede practicarse la autorretención (tal como sucede en el reembolso de gastos), corresponderá al sujeto pasivo que recibe el ingreso, determinar si este es de aquellos susceptibles de incrementar el patrimonio y si sobre los mismos habrá de practicarse la autorretención (Concepto DIAN 059219 de 2013).

Respecto de los ingresos percibidos para terceros, ha establecido la DIAN, en un análisis aplicable al negocio de intermediación que realizan las agencias de viajes, que aunque el Decreto 862 de 2013 no reguló el tema de los ingresos que se reciben para terceros, no podrá un contribuyente asumir la retención del impuesto sobre ingresos que no son percibidos para sí (Concepto DIAN 038460 de 2013).

- Reembolso de gastos

Dado que en el contrato de mandato el mandatario está realizando un encargo por cuenta de otro (mandante), es común que el primero incurra en costos o gastos relacionados directamente con el objeto del contrato; dichos gastos deberán ser reembolsados por el segundo (Concepto DIAN 52909 de 2014). El siguiente es el tratamiento que ha de dársele a dicho reembolso de gastos:

IVA: El monto de dicho valor reembolsable, por no provenir de una operación de venta ni de una prestación de un servicio, no será 
generador del impuesto sobre las ventas (IVA). Es de precisar que cuando no existe efectivamente una operación de venta o una prestación de servicios y lo que realmente existe es un reembolso de gastos, no se presentan los supuestos de la obligación de expedir factura y tampoco se concreta el hecho generador del impuesto sobre las ventas. Así mismo, dado que el reembolso proviene de la ejecución de un contrato de mandato y no de un contrato de prestación de servicios ni de una venta gravable, tal partida no integra la base gravable del IVA (Estatuto Tributario artículos 477 y 478).

\section{Retención en la fuente sobre el impuesto a} la renta: Sobre el reembolso de gastos no se efectúa retención en la fuente alguna, toda vez que el mismo no constituye un ingreso susceptible de enriquecer o generar un incremento patrimonial en el mandatario. Lo anterior, por cuanto tal reembolso se genera por un préstamo transitorio que el mandatario hace al mandante, razón por la cual su pago se asemeja a un reintegro de capital (Conceptos DIAN 2012012 de 1998; 8073615 de 2000; 9087927 de 2000). Esto constituye un hecho exento de este gravamen, según lo dispone el inciso 2 del artículo 17 del Decreto 187 de 1975.

Facturación: La solicitud que hace el mandatario al mandante acerca del reintegro o reembolso de gastos no tiene que realizarse mediante la expedición de una factura, pues dichos rubros no hacen parte de la comisión u honorarios que sí debe facturar el mandatario, y que están sujetos al impuesto a las ventas por tratarse de la prestación de un servicio no excluido. Así entonces, dicho reintegro o reembolso puede ser solicitado mediante la expedición de una cuenta de cobro.
Limitación al reembolso de gastos: Ha establecido la DIAN (Conceptos DIAN 094075 de 2008; 039972 de 1996; 014543 de 1998) que no todo gasto puede ser objeto de reembolso. Solo pueden serlo aquellos gastos que siendo propios de una persona son pagados por otra en su nombre y a su cargo. Esta posición indica que, por ejemplo, en materia de deducciones laborales, aunque puede celebrarse un mandato para que un tercero (mandatario) pague las obligaciones laborales del mandante (tomándose este último la deducción por tales conceptos), no puede celebrarse un contrato de mandato en donde el mandatario, por el único hecho de realizar el pago de tales obligaciones laborales, sea quien pueda tomarse la deducción referida (Concepto DIAN 70088 de 2011).

\section{- Retención en la fuente}

En el contrato de mandato, salvo para efectos de lo ya visto para el Impuesto sobre la renta para la equidad -CREE-, donde el beneficiario del pago actúa como autorretenedor (Decreto 1828 de 2013 artículo 2 parágrafo) $\mathrm{y}$ de los pagos hechos a autorretenedores del sistema financiero (Decreto 700 de 1997), el mandatario es quien siempre practicará las retenciones en la fuente sobre el impuesto a la renta, ventas y timbre al momento del pago o abono en cuenta, teniendo en cuenta para el efecto la calidad del mandante (Decreto 3050 de 1997 artículo 29 inciso 1).

Esta norma ha sido duramente criticada por cuanto implica que el mandatario deba siempre, al momento de efectuar un pago o un abono en cuenta, revelar las calidades de su mandante (Concepto DIAN 053502 de 2011), lo cual desvirtuaría la calidad de oculto del encargo si se tratare de un mandato sin representación. Así pues, podría darse el ca- 
so de que un mandatario sin representación (no autorretenedor), que actúa por cuenta de su mandante (quien es autorretenedor), deba solicitar que quien le realiza un pago o le hace un abono en cuenta no le practique retención, toda vez que su mandante goza de la calidad de autorretenedor. Indudablemente, al hacer esto, deberá el mandatario revelar la calidad del mandante ante terceros, por lo que pierde sentido la figura del mandato sin representación.

La disposición normativa que da lugar a esta situación -el apartado "teniendo en cuenta para el efecto la calidad del mandante"- (Decreto 3050 de 1997 artículo 29 inciso 1) fue demandada ante el Consejo de Estado por violar las normas que fundamentan su reglamentación, específicamente, aquellas que permiten que el contrato de mandato sea no representativo (Sentencia CE-18760 de 2014). El Consejo de Estado determinó no anular la norma atacada, puesto que en las relaciones entre el mandante y el mandatario, este siempre actúa en nombre y representación del mandante, aunque frente a terceros oculte tal calidad. Así mismo, como el mandatario no actúa en nombre propio, así ejerza un mandato oculto, son las calidades del mandante las que determinan si debe o no practicarse la retención en la fuente. Por lo tanto, si el mandante es agente de retención en IVA (Estatuto Tributario artículo 437-2) o gran contribuyente (Estatuto Tributario artículo 562), el mandatario debe practicar la retención (Sentencia CE-18760 de 2014).

Aparte de lo anterior, establece la legislación vigente (Decreto 3050 de 1997 artículo 29 inciso 4) que el mandante practicará la retención en la fuente sobre el valor de los pagos o abonos en cuenta efectuados a favor del mandatario por concepto de honorarios
(Concepto DIAN 000368 de 2015). Sobre los demás pagos que haga el mandante al mandatario, tales como los reembolsos de gastos por la realización del encargo, no debe practicarse retención alguna por expresa disposición del artículo 17 inciso 2 del Decreto 187 de 1975, y en concordancia con la definición de ingreso establecida en el artículo 38 del Decreto 2649 de 1993. Esta postura es compartida por la DIAN, según se acredita en el Concepto DIAN 041736 de 1994). Veamos:

[s]i en cumplimiento de la gestión encomendada el mandatario se compromete a sufragar la totalidad de los costos y gastos necesarios que demande el cumplimiento de su cometido a fin de que sea cumplido a satisfacción, obligándose a su turno el mandante a reembolsar los gastos que el mandato ocasione, (...) es claro que con excepción de la remuneración (comisión) percibida por la gestión realizada, la parte restante no constituye ingreso, puesto que no acrece al patrimonio ni es susceptible de producir un incremento neto del mismo; simplemente lo que se está es realizando el reintegro de valores que en última instancia lo que implican es la satisfacción de una deuda empleando al efecto como modalidad de pago y a opción del mandante, el equivalente en moneda nacional o mediante carta de crédito, lo cual impide a todas luces efectuar retención en la fuente por dicho concepto.

\section{- Obligaciones formales}

En su calidad de agente retenedor, el mandatario ha de cumplir con todas las obligaciones inherentes en calidad de tal, las cuales son: declarar, consignar las retenciones, expedir certificados, llevar contabilidad, entre otras (Decreto 3050 de 1997 artículo 29). La 
obligación formal del mandatario de expedir certificados cobra mayor importancia, pues para que el mandante pueda soportar los respectivos costos, deducciones, impuestos descontables o devoluciones a que tenga derecho, el mandatario deberá expedirle a este una certificación donde se consigne la cuantía y concepto de los mismos avalada por contador público o revisor fiscal.

Dado que el artículo 3 del Decreto 1514 de 1998 no establece la periodicidad con la que se debe expedir la certificación avalada por el contador o revisor fiscal, ni cuál debe ser su contendido, es lógico pensar que esta puede ser expedida por cada período gravable para que sirva como soporte de ingresos, costos, deducciones e impuestos descontables.

Respecto de su contenido, la certificación aludida debe contener, tal como lo establece la norma, "la cuantía y el concepto de que se trate", sin perjuicio de contener otros ítems formales que le den validez a la misma, como lo son la identificación del contador y revisor fiscal, y la firma del mandatario, entre otras.

En relación con la obligación de facturar (Concepto DIAN 02030 de 2009), establece el Decreto 1514 de 1998, en su artículo 3, que independientemente de si el contrato es con o sin representación, el mandatario será siempre quien expida las facturas (Decreto 3050 de 1997 artículo 29).

A modo de ejemplo, en el contrato de encargo fiduciario, a raíz de lo establecido en la Circular Básica Jurídica de la Superintendencia Financiera (Título 5, Capítulo 1, Punto 1.1.), este es considerado como un tipo especial de contrato de mandato, considerando la doctrina que le asiste a la sociedad fiduciaria el cumplimiento de todas las obligaciones formales en su calidad de tal.
Así pues, la DIAN, en Concepto 030811 de 2012, estableció que, en cuanto a la facturación, tanto el fiduciario como el mandatario deben cumplir todas las obligaciones formales, pero en el último caso (mandato), se debe tener en cuenta la calidad del mandante. Igualmente, en el Concepto DIAN 051897 de 2000, estableció la entidad:

[E]n consecuencia la fiduciaria, cumplirá no solo con la práctica de la retención en la fuente al momento del pago o abono en cuenta sino con todas las obligaciones formales tales como declarar, consignar a la administración, expedir certificado y presentar las correspondientes declaraciones. Para efectos de soportar los costos y deducciones a que tenga derecho el fideicomitente, la fiduciaria deberá expedirle una certificación sobre la cuantía de los pagos y sus conceptos. Por lo tanto, no es correcto de conformidad con las normas fiscales vigentes que el agente retenedor sea la entidad fideicomitente.

Si el mandatario adquiere bienes o servicios en cumplimiento del mandato, la factura deberá ser expedida a nombre del mandatario (Decreto 1514 de 1998). Así pues, aunque la facturación por la adquisición de bienes y servicios la debe expedir el tercero a nombre del mandatario, el registro contable por parte del mandante debería hacerse con el NIT de los terceros que le facturaron al mandatario, pues estos son los receptores de los ingresos provenientes de los pagos realizados por el mandante a través del mandatario (Memorando General del Contrato de Mandato. Of. Ignacio Sanín Bernal \& Cía. Abogados).

Dado que el mandante es quien asume la carga fiscal de los ingresos percibidos por el mandatario en desarrollo del contrato, al 
igual que quien solicita costos, deducciones, impuestos descontables y retenciones en la fuente, debe en virtud de lo establecido en el artículo 631 del Estatuto Tributario suministrar la información de terceros en medios magnéticos, para efectos de poder realizar los estudios y cruces de información.

El mandatario, por su parte, está obligado a suministrar la información a que se refiere el literal g) del artículo 631 del Estatuto Tributario y de la Resolución DIAN 000228 de 2013. De manera general, su deber radica en informar a las personas de quiénes se recibieron ingresos para terceros, y de los terceros a cuyo nombre se recibieron ingresos con indicación de la cuantía y demás detalles de los mismos. En ningún caso, la información que debe ser registrada por el mandatario o contratista deberá ser informada por el mandante. Nótese que, como ya se dijo, para efectos civiles y tributarios, se tienen como mandatarios a las sociedades fiduciarias cuando se actúa bajo la figura contractual de encargo fiduciario, y al contratista cuando se actúa bajo la figura contractual del contrato de administración delegada (Resolución DIAN 000228 de 2013 artículo 23.7.2).

\section{- La prueba del mandato}

Tal como se estudió previamente, para efectos civiles y comerciales, el contrato de mandato es consensual y puede celebrarse válidamente, inclusive de forma verbal. En materia fiscal, solo se exige que el contrato conste por escrito cuando se solicitan devoluciones (Decreto 1514-1998 artículo 3 inciso 3). No obstante ello, en la práctica, el hecho de que el contrato no conste por escrito es tomado por las autoridades fiscales como indicio de su inexistencia. Por lo mis- mo, siempre es recomendable documentar el contrato de mandato mediante escrito con fecha cierta.

La DIAN ha establecido (Concepto DIAN 048360 de 2009) que el mandatario debe conservar todos los elementos probatorios necesarios para demostrar que la ejecución de un determinado negocio se adelantaba bajo la figura del mandato y, en especial, cuando la ejecución del mencionado negocio implique que el mandatario reciba dinero en sus cuentas bancarias por cuenta de un tercero. Establece la entidad que, para el caso de un mandato inmobiliario, pruebas tales como el poder otorgado y la promesa de compraventa del bien, entre otros, constituyen prueba de la existencia de tal contrato.

\section{Aspectos contables del contrato de mandato}

La dinámica contable del contrato de mandato ha sido trazada por parte de la Superintendencia de Sociedades mediante Circular Externa 115-006 de 2009, en donde regula la contabilización de los contratos de administración delegada, los cuales son, en sí, un mandato para la administración de una obra civil (Circular Externa Superintendencia de Sociedades 115-006 -2009). Precisa la Circular Externa:

[s]e entiende por contrato de administración aquel que se ejecuta por cuenta y riesgo de la persona natural o jurídica que contrata la obra y en el cual, el contratista es un delegado o representante de aquella. (...) El contrato de administración delegada se considera como un contrato en la modalidad de mandato, mediante el cual, un contratante encarga la ejecución de la actividad que es objeto del contrato, a un contratista bajo 
una remuneración y sin subordinación, en ejercicio de la autonomía de la voluntad.

Esta Circular establece que, con la información suministrada por el contratista, el contratante efectuará los correspondientes registros en su contabilidad (Superintendencia de Sociedades Circular Externa 115-006 de 2009). Así mismo, establece que, en virtud de esta modalidad específica de contrato de mandato, la sociedad contratista ha de llevar dos series de registros contables: por una parte, aquellos que reflejen la aplicación de los recursos recibidos del contratante y las erogaciones hechas con los mismos y, por otra, aquellos que reflejen los honorarios del contratista por los servicios prestados (Superintendencia de Sociedades. Circular Externa 115-006 - 2009):

[1]a sociedad contratista realizará los siguientes registros: a) Los recursos recibidos del contratante, así como las erogaciones incurridas en desarrollo de la operación contratada, se registran en la cuenta del Grupo 94 con cargo a la cuenta 9130 - Contratos de Administración Delegada, del Plan Único de Cuentas y, b) Los honorarios por los servicios prestados los registrará en la cuenta del activo según su naturaleza (efectivo, cuentas por cobrar) contra la cuenta de ingresos 4130- Construcción..

Así mismo, el Consejo Técnico de la Contaduría Pública, en Concepto del 19 de noviembre de 2013, interpretando el tratamiento contable impartido por la Circular Externa antes mencionada, concluyó que: i) el contrato de mandato debe ser reconocido por ambas partes en sus estados financieros mediante la utilización de cuentas de orden (para el mandante las deudoras y para el mandatario las acreedoras); ii) el mandante debe registrar como pasivo (y ya no solo como cuenta de orden) los créditos obtenidos en la ejecución del contrato de mandato, y iii) las operaciones realizadas en virtud del contrato deberán revelarse en las notas a los estados financieros (Concepto Consejo Técnico de la Contaduría Pública 19 de noviembre de 2013).

Así mismo, establece que, contrario a lo que sucede con la contabilización de otro tipo de contratos de colaboración (tal como es el caso del contrato de cuentas en participación), el mandatario no debe reportar, en cuentas de orden, los recursos recibidos $\mathrm{y}$ adeudados al mandante en virtud de la ejecución del contrato de mandato. Por el contrario, estos deben ser registrados como verdaderos activos y pasivos dentro del cuerpo de su balance.

El Consejo Técnico de la Contaduría sugiere, bajo los parámetros del Decreto 2649 de 1993, la siguiente dinámica para el registro contable del contrato de mandato:

Momento en el cual se registra el pago de la obligación
por parte del mandatario:

138025 Pago por cuenta de terceros XXXX

110505 Efectivo XXXX

Momento en el cual se registran los honorarios por parte del mandatario:

$41 \quad$ Ingreso por honorarios $\quad \mathrm{XXXX}$

138025 Pago por cuenta de terceros XXXX

Momento en el cual se registra el pago del mandante al mandatario:

$\begin{array}{lll}110505 & \text { Efectivo } & \text { XXXX } \\ 138025 & \text { Pago por cuenta de terceros } & \text { XXXX }\end{array}$ 
Momento en el cual se registra por parte del mandante:

$\begin{array}{lll}5 & \text { Gastos } & \text { XXXX } \\ 2335 & \text { Costos y gastos por pagar } & \text { XXXX }\end{array}$

Ahora bien, bajo los parámetros de las Normas Internacionales de Información Financiera (NIIF), la contabilización del contrato de mandato varía ligeramente. $\mathrm{Ha}$ establecido el Consejo Técnico de la Contaduría (Concepto Consejo Técnico de Contaduría 2013-286 de 2014) que, bajo el marco técnico normativo incluido en el Decreto 2784 de 2012, el mandatario debe registrar las operaciones que realice en cumplimiento del contrato, diferenciando las partidas que pueden ser reconocidas como activos y pasivos suyos de las que corresponden a activos y pasivos del mandante. Así mismo, establece que deberá registrar como un pasivo, mientras no haya cumplido sus obligaciones contractuales, "los dineros recibidos de los clientes para desarrollar las obligaciones del contrato" y como un activo "los dineros que entregue al subcontratista (...) mientras no reciba la contraprestación respectiva (Concepto Consejo Técnico de Contaduría 2013286 de 2014).

\section{Referencias}

\section{Bibliográficas}

Hinestrosa, F. (2008). La representación. Bogotá: Universidad Externado de Colombia.

\section{Legislación}

Código de Comercio de Colombia.

Código Civil Colombiano.

Decreto 2649 de 1993.

Decreto 3050 de 1997.

Decreto 1514 de 1998.

Circular Básica Jurídica de la Superintendencia Financiera.

Resolución DIAN 011429 del 31 de octubre de 2011.

Resolución DIAN 000228 del 31 de octubre de 2013.

\section{Doctrina especializada}

Superintendencia de Sociedades.

Circular Externa 115-006 de 2009.

Concepto DIAN 041736 de 1994.

Concepto DIAN 039972 de mayo 14 de 1996.

Concepto DIAN 014543 de marzo 6 de 1998.

Concepto DIAN 2012012 de 1998.

Concepto DIAN 052677 de junio 04 de 1999.

Concepto DIAN 051897 del 31 de mayo de 2000.

Concepto DIAN 8073615 del 2000.

Concepto DIAN 9087927 de 2000.

Concepto DIAN 0003264 de 2002.

Concepto DIAN 071921 del 5 de octubre de 2005.

Conceptos DIAN 094075 de septiembre de 2008.

Concepto DIAN 002100 del 11 de noviembre de 2008.

Concepto DIAN 02030 del 9 de marzo de 2009.

Concepto DIAN 048360 del 16 de junio de 2009. 
Concepto DIAN 053502 del 21 de julio de 2011.

Concepto DIAN 70088 del 12 de septiembre de 2011.

Concepto DIAN 030811 del 14 de marzo de 2012.

Concepto DIAN 037545 de junio de 2012.

Concepto DIAN 038188 del 14 de junio de 2012.

Concepto DIAN 037545 de junio de 2012.

Concepto DIAN 038460 del 24 de junio de 2013.

Concepto DIAN 059219 del 18 de septiembre de 2013.

Concepto DIAN 057035 del 10 de septiembre de 2013

Concepto DIAN 065122 del 11 de octubre de 2013.

Concepto DIAN 52909 del 29 de agosto de 2014.

Concepto DIAN 066917 del 12 de diciembre de 2014.

Concepto DIAN 000368 del 13 de marzo de 2015.

Consejo Técnico de la Contaduría Pública Concepto del 19 de noviembre de 2013.

Consejo Técnico de la Contaduría Pública Concepto del 23 de septiembre de 2014.

\section{Jurisprudencia}

Consejo de Estado. Sección Cuarta. Sentencia del 16 de septiembre de 2010. C.P. Carmen Teresa Ortiz de Rodríguez.

Consejo de Estado. Sección Cuarta. Sentencia del 6 de noviembre de 2003. C.P. María Inés Ortiz Barbosa.

Consejo de Estado. Sección Cuarta. Sentencia del 6 de marzo de 2014. C.P. Martha Teresa Briceño de Valencia.

Consejo de Estado. Sección Cuarta. Sentencia del 3 de abril de 2014 C.P. Martha Teresa Briceño.

Corte Suprema de Justicia. Sala de Casación Civil. Sentencia del 17 de Junio de 1937.

\section{Documento especializado}

Ignacio Sanín Bernal Abogados (2009). Memorando General de Mandato. Medellín. 